\title{
Pelvic congestion syndrome, treatment choices
}

\section{Abstract}

pelvic congestion syndrome PCS occur due to ovarian varicosities and causes a chronic recurrent lower abdominal discomfort, sometimes this pain increases with menstruation, there is various managements choices, here we report a case of PCS that was diagnosed and managed by conventional surgery.

Keywords: pelvic congestion syndrome, ovarian varicosity, pain lower abdomen, pelvic pain, menstruation, diagnosed, conventional surgery
Volume 3 Issue 4 - 2016

\author{
Muhammad Turki Al Abd, Muhammad Assem \\ Kubtan \\ Department of Surgery, Syrian Private University, Syria
}

Correspondence: Muhammad Assem Kubtan, Department of Surgery, Medical Faculty, Syrian Private University, Damascus, Syria, Tel 0096394427I215, Email makubtan@gmail.com

Received: August 08,2016 | Published: November 24, 2016
Abbreviations: PCS, pelvic congestion syndrome; CPP, chronic pelvic pain; CT, computed tomography

\section{Introduction}

Chronic pelvic pain (CPP) affects approximately one third of all women and accounts for $20 \%$ of outpatient gynecology appointments. ${ }^{1}$ pelvic congestion syndrome is one of many causes of chronic pelvic pain, Gonadal vein dilation may be seen in as many as $10 \%$ of women, more than half of whom may go on to develop PCS, ${ }^{2}$ PCS typically affects multiparous women of reproductive age. Most women present with noncyclic lower abdominal or pelvic pain, usually described as a dull ache or fullness that lasted between months and years, this pain is often exacerbated by prolonged standing, coitus, menstruation, and pregnancy. ${ }^{1}$ Mostly patient attends gynecology clinics and receives conservative treatment of hormonal nature unless suspicion of PCS is raised. ${ }^{3,4}$ We present two cases of PCS transferred to our surgical clinic for consultation.

\section{Case presentation}

\section{Case I}

A 24years old married female Gravida 3para 3 having three children, attended our clinic with a seven months history of recurrent lower abdominal pain associated with feeling of fullness and distention in the lower abdomen exacerbated by menstrual periods and associated with increasing menstrual bleeding. She had no gastrointestinal, neurological or musculoskeletal symptoms, no previous family history of reproductive system disturbances or malignancy (Figure 1).
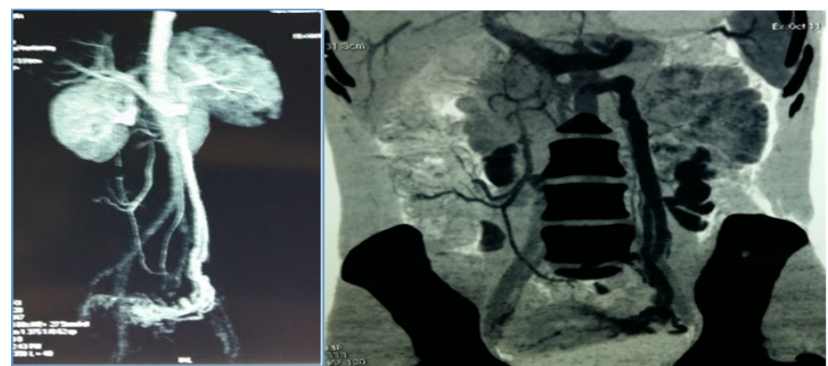

Figure I Case I multi slices CT angiography showing dilated pelvic veins extending to $L t$ ovarian vein.

\section{Case 2}

A 31years old married female Gravida 4 para 4 having four children, presented to our clinic with a similar history of six years of chronic lower abdominal pain, exacerbated with menstruation the patient complain of vaginal discharge and a history of extensive lower extremity varicose veins in left leg treated two years back by stripping of long saphenous vein and multiple avulsion (Figure 2).

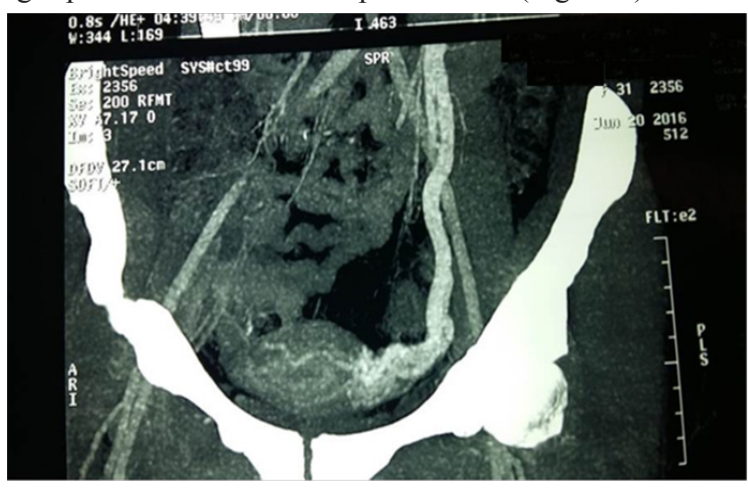

Figure 2 Case 2 multi slices CT angiography showing dilated pelvic veins extending to dilated Lt ovarian vein.

\section{Investigations}

Specific investigation for both patients consisted of Colored Ecko Doppler followed by performance of Multislice Computerized Angiography, proved the presence of pelvic varicosities with dilated Lt Ovarian vein.

\section{Method of treatment}

Both cases treated by conventional surgery consisted of Lt sided periumbilical transverse oblique $8 \mathrm{~cm}$ Incision, muscle split followed by dissecting the retro peritoneum wall anteriorly, without penetrating the peritoneal cavity Figure 3, the Lt Ovarian Vein with the associated varicose plexus exposed Figure 4, dissected easily ligated and divided between two absorbable ligatures, hemostasis achieved and the abdominal wall closed in layers without drainage Figure 5. The whole time of surgery did not exceed 25 minutes in both cases, 6hours post operatively the patients were allowed home, with analgesic prescription, and advised to be on fluids only for that night. 


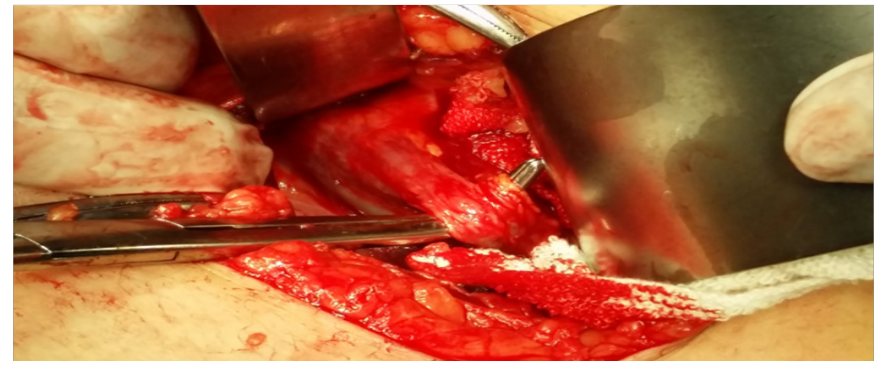

Figure 3 Exposing Lt ovarian dilated vein through retroperitoneal approach.

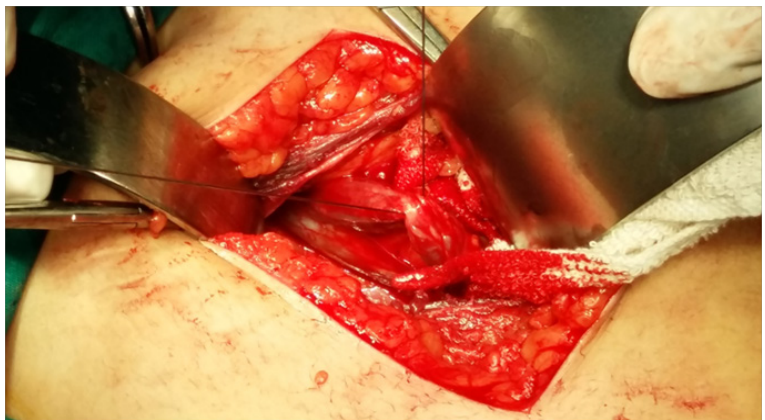

Figure 4 Passing a ligature around dilated ovarian vein in preparation to ligation and division.

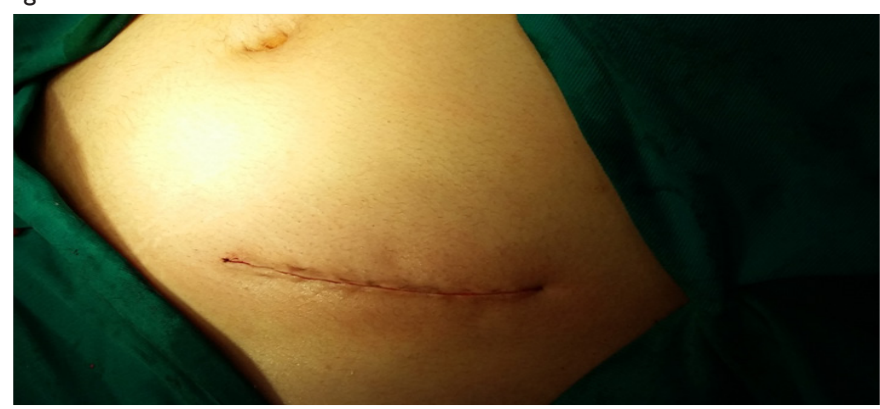

Figure $\mathbf{5}$ Completing the surgical procedures with subcuticular skin closure.

\section{Follow up in the out patients clinic}

One week later the patients were seen in the out patients clinic. Patients were reviewed in the out patients clinic one week later, they were in good health, the pelvic symptoms have disappeared. Both patients were reviewed in the outpatient's clinic in 2 months and 6 months later, and they were symptoms free.

\section{Discussion}

PCS is a commonly seen by gynecologists, with various presentation, and frequently there is delay in making the diagnosis, many decades back conservative treatment was the only choice offered to patient, when condition goes out of control the only recommendation would be Hysterectomy, with the advances of investigation consisting Colored Ecko Doppler and multi slice CT Angiography, it became much easier to make up the diagnosis. The purpose of writing this report is to discuss the values of conventional surgery in dealing PCS invasively when other means of none invasive treatment has failed. We are aware that talking about conventional surgery when there is a feasibility of venous embolization, just like swimming against the tide..$^{5-8}$

A decision of invasive treatment should take in account many factors, commonly almost all the papers we reviewed stated the values of embolization of the Lt ovarian dilated vein with coils, and less by the use of Sclerosant, but scarcely none mentioned the time, the risk factors, the learning curve of the interventionist, the exposure to $\mathrm{x}$ ray involving the patient and the operator, the reported complications may be encountered, the cure rate and the cost.

We believe that insisting on embolization should not be adhered to all the time since it is at least in the law income countries represent heavy burden on the patient as well as on the national health authority, in our part the globe it is considered to be extremely expensive, time consuming in the catheterization department, and the risk of harming the Lt renal or the ovarian vein can't be ignored. Surgical intervention is a straight forward procedure, easy to learn, easy to perform, with absolute low morbidity, and almost nil mortality.

\section{Acknowledgements}

None.

\section{Conflict of interest}

The author declares no conflict of interest.

\section{References}

1. Phillips D, Deipolyi AR, Hesketh RL, et al. Pelvic congestion syndrome: etiology of pain, diagnosis, and clinical management. $J$ Vasc Interv Radiol. 2014;25(5):725-733.

2. Shelkey J, Huang C, Karpa K, et al. Case report: pelvic congestion syndrome as an unusual etiology for chronic hip pain in 2 active, middleage women. Sports Health. 2014;6(2):145-148.

3. Farquhar CM, Rogers V, Franks S, et al. A randomized controlled trial of medroxyprogesterone acetate and psychotherapy for the treatment of pelvic congestion. Br J Obstet Gynaecol. 1989;96(10):1153-1162.

4. Nicholson T, Basile A. Pelvic congestion syndrome, who should we treat and how? Tech Vasc Interv Radiol. 2006;9(1):19-23.

5. Ahmed K, Sampath R, Khan MS. Current trends in the diagnosis and management of renal nutcracker syndrome: a review. Eur J Vasc Endovasc Surg. 2006;31(4):410-416.

6. Cheong Y, Stones WR. Chronic pelvic pain: aetiology and therapy. Best Pract Res Clin Obstet Gynaecol. 2006;20(5):695-711.

7. Sichlau MJ, Yao JS, Vogelzang RL. Transcatheterembolo therapy for the treatment of pelvic congestion syndrome. Obstet Gyneco. 1994;83:892896.

8. Kim HS, Malhotra AD, Rowe PC, et al. Embolotherapy for pelvic congestion syndrome: long-term results. J Vasc Interv Radiol. 2006;17(2 Pt 1):289-297. 